\title{
Analysis of User Preferences for Smart Home Products in Minshuku
}

\author{
Diyan Xian ${ }^{*}$, Shihua $\mathrm{Xu}^{2}$ \\ ${ }^{1}$ Department of Art and Design, Wuyi Universtiy, Jiangmen, China \\ ${ }^{2}$ Department of Art and Design, Wuyi Universtiy, Jiangmen, China
}

\begin{abstract}
Smart Home Products(SHP) have been developing for more than ten years and getting more favored by customers. There are many kinds of products with different functions. In addition to ordinary home users, Minshuku hosts, hotel owners also employ smart home products to manage the houses/apartments. There may be differences in the demand preferences and types of smart home products between Minshuku users and home users. This paper classified the smart home products by functions, and analyzed the demand preferences of minshuku users for these products through questionnaire survey and interviews. Exploring these user requirements and scenarios in which product used can promote the R \& D and the iteration of intelligent products.
\end{abstract}

\section{Introduction}

With the rapid development of smart home industry and the trend of consumption upgrading, Smart Home Products (SHP) are favored by more ordinary families. The emergence of smart home products, to a large extent, solves the user's problems. Most users willing to buy and install smart products for their residence [1]. In recent years, with the growth of urban minshuku, more minshuku hosts choose to install smart home products in their minshuku.

Minshuku, also named B \& B or Homestay, is a popular concept in tourism market during these years [2]. Usually refers to sharing residential spare rooms of host, to provide special and localized accommodation services for visitors or guest. Every group of visitors need to contact the minshuku host in advance for reservation, check-in and check-out. If the hosts of minshuku are not busy, they may meet visitors and bring them to the minshuku. If the host cannot stay in minshuku all the time, they prefer arranging the check-in, check-out by telephone, messages, e-mail and other types of communication. Hosts can operate more than one minshuku, which may located in the same building or scattered in different areas of the city. For this case, Intelligent Password Locks had been developed for hotels, minshuku, apartments, etc. Intelligent password locks are very convenient for hosts or managers to manage their houses/apartments remotely [3]. In addition to its localized characteristics, minshuku also needs to be clean, comfortable and convenient to be more popular with visitors. If there are smart home products in the minshuku, they can enhance the experience of the visitors, and also conducive to the operation and maintenance of the minshuku for the hosts.

\section{TypeS OF SMART HOME PRODUCTS}

There are many different kinds of Smart Home Products and these products developed by various brands. Smart home products can work alone or link to the mobile terminal for control. Different products can also be connected through wireless network or Internet of things to integrate as a smart home system [4]. The system is controlled by the control center, which is synchronized with the mobile App. Users can control it locally or remotely.

\section{FOUNDS OF SMART HOME PRODUCTS}

\subsection{Intelligent electrical control}

It adopts weak current control and strong current control, and can control a variety of electrical appliances by remote control, timing and other control methods. For example, intelligent temperature control, no matter where people are, can remotely control the home air conditioning, floor heating, fresh air and other systems, to provide users with a constant temperature and comfortable indoor environment [5]. It can also automatically control when people go out, turn off the lights, turn off the air conditioner, and automatically turn on the air conditioner when they get home, saving energy consumption through remote monitoring. Intelligent lighting control can be preset a variety of modes, using remote control, voice control, and even sensors to detect whether a person is at home and automatically switch on and off. A variety of intelligent control methods are used to control the lighting

*Xiandy2@aliyun.com 
scene effects such as the switch and dimming of the whole house and local lights.

\subsection{Security monitoring products}

This kind of products implement automatic monitoring and management of security system through various sensors. In case of fire, harmful gas leakage, theft and other accidents, the security monitoring system can implement automatic alarm. When the user is not at home, he can also view the monitoring video of the gate in real time through the computer, mobile phone, etc. and remote control[6]..

Smart door lock and smart cat's eye (camera) can remotely control the opening and closing of the door through mobile phone, tablet and other terminals. The door with intelligent cat's eye can even replace the home walkie talkie and security camera. When someone outside the door presses the doorbell or the user presses the home key, the image outside the door will be displayed immediately users can talk with visitors through remote video. Face recognition function can also set in this kind of product if it's for a family[7]. However this function is not necessary for Minshuku because the visitors are probably difference every time. There might be security vulnerabilities in this technology if the of face ID of guests were obtained by others.

\subsection{Intelligent entertainment products}

These products are usually embedded with AI recognition system, and users can use voice to demand audio, video or switch TV channels through gestures[8]. the TV can even automatically identify the user's position in the living room and automatically rotate the screen to adjust the best viewing angle for them. Smart speaker system combines MP3, FM, mobile phone, computer and other sound sources, so that each room can hear wonderful background music and immerse in the corresponding atmosphere. In some hotels and apartments, customized welcome voice and background music will be accompanied by curtain automatic opening.

\subsection{Intelligent cleaning products}

This category included intelligent sweeping robot, air purifier, induction faucet and intelligent toilet, etc. At the beginning of its launch, the cleaning ability and one-time cleaning efficiency of the intelligent robot were questioned. However, with the progress of technology, the intelligent cleaning robot can automatically identify the map of the home, [9].plan the cleaning route, and improve the one-time cleaning efficiency. Ueser's voice interaction with swipping robot were also developed recently [10]. In addition to cleaning dust, the Cloud Whale automatic mopping machine can also clean the floor and automatically clean the rags. Intelligent toilet with selfcleaning function[11], such as Kohler, Toto, XiaoMi and other similar products applied electrolytic water sterilization technology to clean and deodorize.

\subsection{Others, Intelligent watering /feeding system}

Intelligent watering system can be set to automatically water every few days. When traveling or on business, or too busy to take care of the garden, users can check the status of their home on the App, and press the automatic watering button to water the whole garden according to the set mode. If keeping a pet, Automatic feeder can be prepared to feed the cat and dog automatically [12]. When both the Minshuku host and the visitor are away, the pet can also get food and water on time.

\subsection{System integration control}

In line with the purpose of effectively improving the practicability of the product, minimizing the cost and maximizing the function, users can use a terminal or app to control lighting, electrical appliances, security, entertainment, cleaning and other functions in the system integration smart home products [13]. As show in Figure1, Xiaomi smart home system can switch Air conditioner, Water Purifier, Washer \&dryer and other electrical appliances through one intergraded smart APP [14]. Let APP identifies appliances in advance, it can control appliances of the same brand or other brands. Huawei also developed LiteOS which can be widely used by individuals, families, and businesses [15].This greatly facilitates ordinary home users and Minshuku users, saves multiple remote controls, and only needs to operate one terminal.

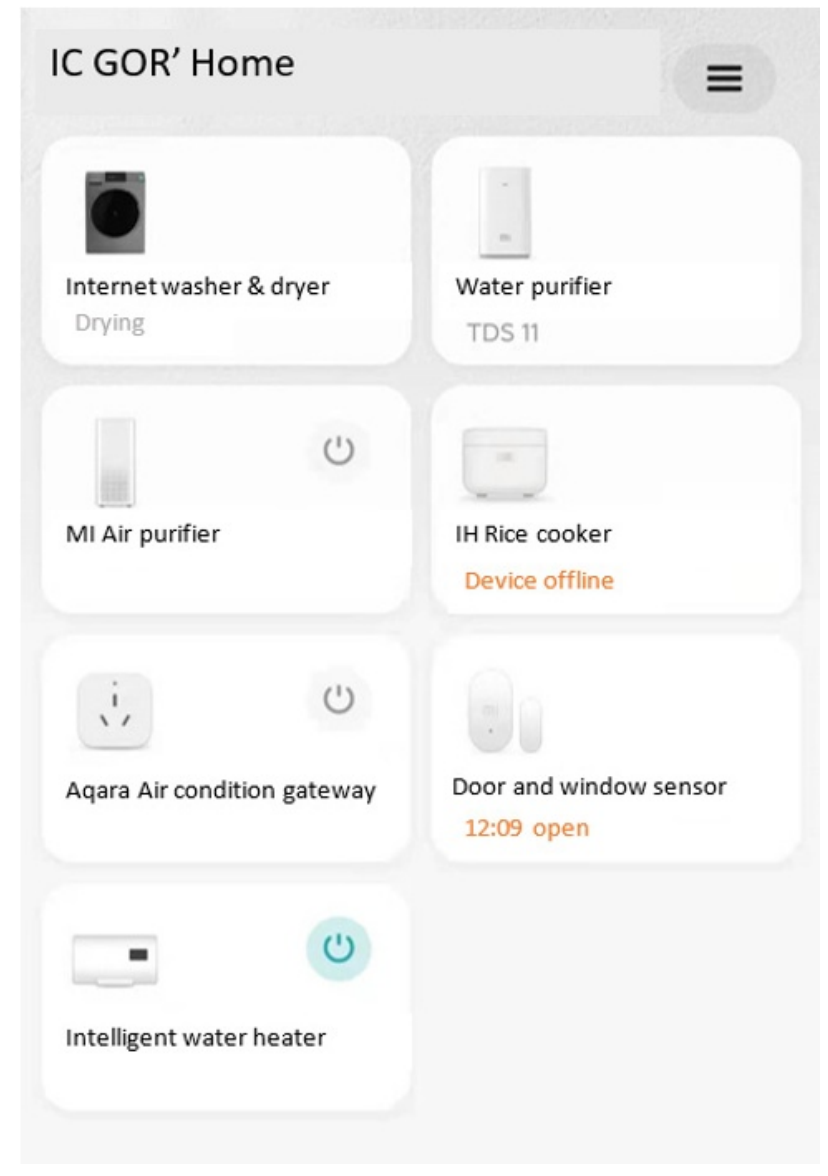

Figure 1. Xiaomi Smart Home System APP 


\section{Technology implementation}

Smart home products use microcontroller to process all kinds of environmental information provided by sensor system for feedback or task execution. Easy to operate, reduce costs, can improve efficiency. (Wang jiluo) the home gateway can connect the external network through Ethernet, GPRS and WiFi, and has the ability of system management; the control terminal has the ability of local control and display, and has the ability of measuring power consumption information, controlling electric lights and switches, TV, air conditioning and other electrical equipment. The current network is mainly $4 \mathrm{G}$ network. When $5 \mathrm{~g}$ Internet of things is realized, smart home products will be further developed and more popularized.

\section{Research process}

Through questionnaires and interviews, a total of 40 minshuku users participated in the survey. Corresponding to the types of smart home products (SHP) listed above, 5 different types of research products in this investigation included, which were intelligent electrical control, intelligent security, intelligent cleaning, intelligent electrical appliances, etc. Users also asked to compare various factors five factors of various types of products: Price, Function, Quality, Service, Appearance, were compared.

\section{Date and analysis}

The gender ratio of users participating in the survey is balanced, $80 \%$ are in the age group of $29-40$, and $20 \%$ are over 40 . All the investigators have used or learned about the above intelligent products. The results were list in table1.

Table1. Products PARTICIPANTS WILLING TO BUY

\begin{tabular}{|c|c|c|}
\hline $\begin{array}{l}\text { Product } \\
\text { Category }\end{array}$ & Products & $\begin{array}{c}\text { Proportion of All } \\
\text { Survey } \\
\text { Participants }\end{array}$ \\
\hline \multirow{2}{*}{$\begin{array}{l}\text { A. Intelligent } \\
\text { electrical control } \\
\text { products }\end{array}$} & $\begin{array}{l}\text { Intelligent lighting } \\
\text { control }\end{array}$ & $45 \%$ \\
\hline & $\begin{array}{l}\text { Intelligent power } \\
\text { control }\end{array}$ & $60 \%$ \\
\hline \multirow{2}{*}{$\begin{array}{l}\text { B. Security } \\
\text { monitoring } \\
\text { products }\end{array}$} & Intelligent door lock & $80 \%$ \\
\hline & Smart cat's eye & $40 \%$ \\
\hline \multirow{2}{*}{$\begin{array}{l}\text { C. Intelligent } \\
\text { entertainment } \\
\text { products }\end{array}$} & Smart speaker & $20 \%$ \\
\hline & Smart set top box & $40 \%$ \\
\hline \multirow{3}{*}{$\begin{array}{l}\text { D. Intelligent } \\
\text { cleaning products }\end{array}$} & $\begin{array}{l}\text { Mopping / sweeping } \\
\text { robot }\end{array}$ & $60 \%$ \\
\hline & $\begin{array}{c}\text { Induction faucet with } \\
\text { hand sanitizer }\end{array}$ & $50 \%$ \\
\hline & Intelligent toilet & $40 \%$ \\
\hline \multirow{2}{*}{$\begin{array}{l}\text { E. Others, } \\
\text { Intelligent watering } \\
\text { /feeding system }\end{array}$} & $\begin{array}{c}\text { Intelligent irrigation } \\
\text { system }\end{array}$ & $15 \%$ \\
\hline & Intelligent pet feeder & $20 \%$ \\
\hline $\begin{array}{c}\text { F. Integration } \\
\text { Smart home control } \\
\text { System }\end{array}$ & & $30 \%$ \\
\hline
\end{tabular}

Intelligent electrical control products, Intelligent lighting control and Intelligent power control drew the attention of $45 \%$ and $60 \%$ users respectively, because these SHP would save energy and easier to be remotely control. Without considering the budget, $90 \%$ of Minshuku users considered smart door lock as a necessary product, and 50\% of users willing to buy smart cat's eye, which belonged to the type of security system. $60 \%$ of Minshuku users would like to choose intelligent Mopping/sweeping robot, and $50 \%$ of them preferred to purchase Induction faucet. Even the expensive intelligent toilets were picked by $40 \%$ of the users. While the other SHP, Intelligent watering /feeding system were not so attractive to the Minshuku users. Maybe not all of them keeping flowers or pets. Similar situation of Integration Smart home control System among Minshuku users.

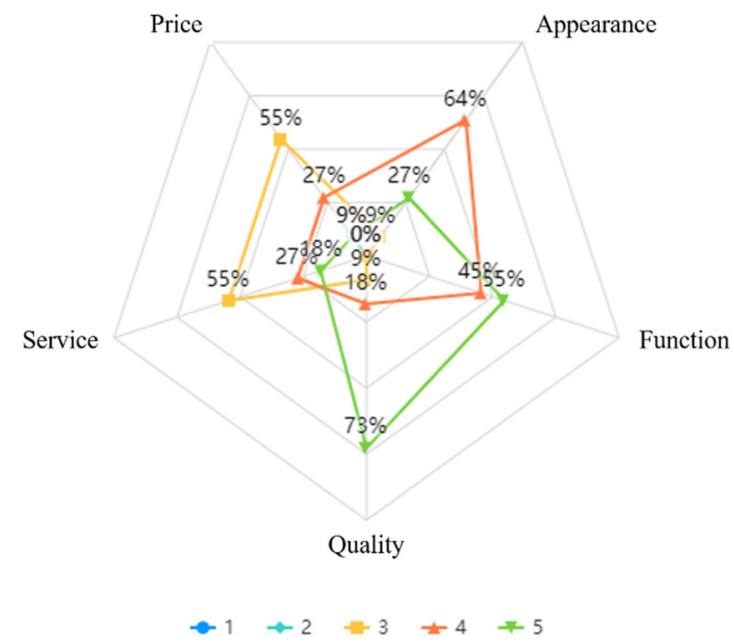

Figure 2. Factors Affected the Users' Preference

Users were also asked to compare five factors of various types of products: Price, Function, Quality, Service and Appearance. Their preferences were collected and showed in the chart in Figure1. From 1 to 5 stands for the importance of the factors. The higher the point, means the factors were more importance. $75 \%$ of them consider the quality of products were very importance, and 56\%of them put the functions very importance. $78 \%$ of them consider the appearance of the products matters. That might because the appearance of the products needed to be consistency with decoration style of the whole Minshuku.

$35 \%$ of the participant used smart home products for the pursuit of technology trend, the other part is to experience a convenient lifestyle, and some prefer the SHP, because the functions of smart home products made their life more convince then previous products did. $60 \%$ of the user did not care about the SHP were from the same brand or developed by same company. Usually, if all Smart home product are from same brand, these products can easily be integrated as one smart home system. If the products are come from different brand or company, the compatibility of different products could be a problem. 


\section{DISS DISSCUSSION AND CONCLUSION}

The results indicated that most of the products selected by the users are generally considered as the basic demand in the category of intelligent security, especially the intelligent password lock. The intelligent door lock can save the time for hosts waiting and meeting the visitors, sending the key, which is convenient and time-saving. The monitoring outside the gate can play a role of safety protection. The landlord of the house and lodging can control the entry and exit of the tenants, cleaning personnel and maintenance personnel directly and conveniently through such kind of (SHP).

The price of (SHP) was also the main consideration for the users. Because a certain proportion of the Minshuku is the property leased by the hosts, not their own properties. Investment in intelligent products is not necessarily, and maintenance costs will also be required in the process of use. On the other hand, the Minshuku hosts needed to consider the impact on the apartment/house when installing SHP. Therefore, most hosts will choose the independent products or a group of smart products, less likely to choose integrated embedded smart home control system. Because the latter needs to be installed by renovation, or the wall might be damaged then repaired for the circuit to be installed to integrate multiple electrical components. Smart home products that are easy to install and disassemble are favored by hosts. On the other side, if the host can choose an integrated smart home system while making the renovation for Minshukus, it's the best time to imbedding the smart home system. As long as products provided by different company or brand are compatible in one system, users can choose product freely. Huawei is building an open network connecting people, things and cloud, which can realize the interconnection of multi brand smart home products or devices. Hopefully, the demands and preferences of Minshuku users can be satisfied by the R\&D of these theology leading companies

In a word, Minshuku users hope to be able to remotely manage the security issues. The core demand preferred by Minshuku users were to achieve security, cleaning, energy saving. Other aspects of intelligent products, entertainment and other products are relatively less biased. Enterprises in the research and development of products can be targeted at this type of user groups to research and development, product update iteration, in order to better meet the needs of users. Focusing on the quality and product stability improvement, sometimes even more important than the new functions for Minshuku users.

\section{Acknowledgment}

This paper was financially supported by 2019 Teaching Quality and Reform Project of Wuyi University, Project No. JX2019017; and 2019 Jiang Men Natural and Basic Theoretical Discipline Research Project, Project No. 2019030101740008889.

\section{References}

1. RJ Robles, T Kim, "Applications, systems and methods in smart home technology: A Review ", Int. Journal of Advanced Science And Technology, 2010

2. M Wang. "Some thoughts on the design of homestay" J, Dazhong Wenyi , 2015, Vol.19

3. D Yang; "Design of intelligent door lock based on Bluetooth" Digital communication world, 2020, Vol.184(04) pp.292-292.

4. El Park; Y Cho; J Han; S J Kwon "Comprehensive Approaches to User Acceptance of Internet of Things in a Smart Home Environment" IEEE Internet of Things Journal ( Volume: 4, Issue: 6, Dec. 2017).

5. R Ford, Marco Pritoni, A Sanguinetti, B Karlin, "Categories and functionality of smart home technology for energy management."

6. G. Chang, Y.Zhai; "Design of intelligent door lock control system based on Bluetooth " Electronic products world, 2015, Vol (005) pp.: 41-44

7. G. Jia, D. Wei and Y. Wang; "Design and development of intelligent door lock identification system" Computer engineering and design; 2019, Vol 40(007) pp.:2094-2100.

8. https://smarthome.ofweek.com/2021-02/ART-910068330-30485685.html

9. H. Zhao, Y.Liu and C.Pu,'Development status and Prospect of floor sweeping robot "Information and computer (theoretical Edition), 2016, $\operatorname{vol}(012)$ pp:167-168.

10. K. Ma, R. He and C. Ma;. Research on experience design of home intelligent sweeping robot based on voice interaction". Packaging engineering, 2020, v.41; Vol432 (18) pp: 129-135

11. Y.Luo; "Three treasures of smart home: smart toilet". China elderly, 2019, vol (008): pp.51-51

12. F. Chen, "Intelligent pet feeder with remote control by mobile phone". Rural science experiment, 2019, 000 (008): 103-104

13. J.Wang; "Design and implementation of embedded smart home control system " Harbin Institute of technology

14. https://home.mi.com/index.html

15. https://www.huawei.com/minisite/liteos/cn/smartho me.html 